\title{
Preconcentration and Direct Determination of As and Bi in Aqueous and Solid Samples Using Hydride Generation Atomic Fluorescence Spectrometry
}

\author{
Kazem Kargosha` and Abolfazl Valadkhani \\ Analytical Chemistry Department \\ Chemistry and Chemical Engineering Research Center of Iran \\ Pajuhesh Blvd., 17th km Tehran-Karaj Highway, Tehran, Iran
}

\section{INTRODUCTION}

The direct determination of elements in solid samples is a quick method, the digestion process is eliminated or diminished, and very beneficial in case of amount of material available and time used for on-line systems (1). The analysis of solid samples with non-direct methods demands wet or dry digestion processes for atomic spectrometry systems. Due to the disadvantages such as contamination, possible analyte loss, incomplete analyte recovery, sample dilution, and more time requirement, atomic spectrometry (AS) methods may not be efficient, reliable, and sensitive enough for many applications. Some applications of these techniques are reviewed in the literature (2-5). Inductively coupled plasma (ICP), neutron activation analysis (NAA), laser ablation (LA), and electrothermal vaporization (ETV) coupled with inductively coupled plasma mass spectrometry (ICP-MS) are powerful, efficient, fast, and less time-consuming analytical instrumental methods for the direct determination of heavy metals in solid samples and do not require sample pretreatment. However, their use has not been extensively applied to heavy metals determination in particulate matter because of their higher cost (2-5).

Another prominent technique, which may be used in this case, is hydride generation coupled to atomic absorption spectrometry (HGAAS) or atomic fluorescence spectrometry (HGAFS) (6-8). Both

*Corresponding author.

E-mail:k.kargos@ccerci.ac.ir@

\begin{abstract}
The present work describes the direct determination of arsenic and bismuth in solid and liquid samples using a lab-made hydride generation accessory in combination with atomic fluorescence spectrometry (HGAFS) Solid samples of talc, bismuth subcitrate, lithium carbonate, dust, soil, liquid waste, and tap water were analyzed. These samples were also analyzed using the hydride generation accessory combined with atomic absorption spectrometry (HGAAS). The limits of detection for HGAFS were $0.32 \mathrm{ppb}$ and $0.30 \mathrm{ppb}$ for As and $\mathrm{Bi}$, respectively. The method offers on-line determination, direct solid sample analysis, preconcentration of the liquid samples, requires low amounts of sample in comparison to nondirect analysis techniques, is less costly and less complex in comparison with other direct analysis techniques. The method is capable of direct powder solid sample analysis and the recoveries were between $95 \%$ to $99.6 \%$. The RSD $(n=5)$ for As was $1.46 \%$ and for Bi $1.35 \%$. The calibration curves were linear in the range of 1.0-100 ppb for As and 1.0-200 ppb for Bi.
\end{abstract}

of these methods are widely used for the trace determination of hydride-forming elements. The benefits of these techniques are simplicity and good sensitivity, selectivity, relative freedom from interferences, and low cost. Reasonably low detection limits can be obtained even with a simple hydride generation setup. HGAFS is the most reliable method for deter- mining elements such as As, Se, Sb, $\mathrm{Bi}, \mathrm{Pb}, \mathrm{Sn}, \mathrm{Ti}$, and Ge (6-8). Arsenic and bismuth are among the elements for which trace level determination is of great interest. Arsenic mostly occurs in minerals and causes pollution from industries and bismuth is widely used in various medicinal compounds and in various other fields of industry. Hence, the presence of $\mathrm{As}$ or $\mathrm{Bi}$ in the environment and the food chain can lead to high exposure for humans (9). The present work aims to verify the utility of HGAFS for the determination of arsenic and bismuth in solid and liquid samples.

\section{EXPERIMENTAL}

\section{Instrumentation}

All atomic absorption spectrometry analyses were performed using a PerkinElmer ${ }^{\circledR}$ AAnalyst $^{\mathrm{TM}} 800$ spectrometer (PerkinElmer, Inc., Shelton, CT, USA). Atomic fluorescence analysis was performed using the XGY® $1011 \mathrm{~A}$ atomic fluorescence instrument (Physical-Chemical Prospect Institute of Beijing Land Estate and Mineral Product Branch, Beijing, P.R. China). The lab-made hydride generation schematic is shown in Figure 1. The different delivery routes of the hydride gases to the atomization zone of these two atomic methods are also presented in Figure 1 (a and $b$ ). The reaction vessel, gasliquid separator, and quartz $t$-tube were made in the laboratory using different designs, then optimized and used for on-line configuration.

The HCL lamp for arsenic was operated at $197.2 \mathrm{~nm}$ with a slit width of $1 \mathrm{~nm}$, and for bismuth was operated at $223.1 \mathrm{~nm}$ with a slit 
width of $0.5 \mathrm{~nm}$. A Buchi ${ }^{\circledR}$ Rotavapor ${ }^{\circledR}$ R-215 rotary evaporator (BÜCHI Labortechnik AG, Flawil, Switzerland) and Multiwave ${ }^{\circledR} 3000$ microwave oven (Anton Paar $\mathrm{GmbH}$, Austria) were used for the vaporization and drying processes

\section{Reagents and Stock Standard Solutions}

All reagents used were of analytical grade purity. All ultra-pure water used for sample preparation and dilutions was obtained with a Milli-Q ${ }^{\circledR}$ water purification system (Millipore Corporation, USA). The stock standard solution of arsenic was $1000 \mathrm{mg}$ As $\left(\mathrm{As}_{2} \mathrm{O}_{3}\right.$ in $\left.\mathrm{H}_{2} \mathrm{O}\right)$ Titrisol ${ }^{\circledR}$ (Merck, Germany) and diluted in $1 \mathrm{~L}$ of ultra-pure water. Bismuth stock standard solution was $1000 \mathrm{mg} \mathrm{Bi}\left(\mathrm{Bi}\left(\mathrm{NO}_{3}\right)_{3}\right.$ in $0.5 \mathrm{M}$ $\left.\mathrm{HNO}_{3}\right)_{\text {Titrisol }}^{\circledR}$ (Merck), diluted in $1 \mathrm{~L}$ of $1 \mathrm{M} \mathrm{HCl}$. The reductant solutions were prepared daily by dissolving appropriate amounts of sodium borohydride powder (Merck, >98\%) in $\mathrm{NaOH}(1 \%)$ solution.

\section{Methods Preparation}

The working standard solutions were prepared immediately before use by stepwise dilution with a $1: 1$ mixture of $1 \mathrm{M}$ hydrochloric acid and sulfuric acid for arsenic and $1 \mathrm{M}$ hydrochloric acid for bismuth. With the conventional method, $4 \mathrm{~mL}$ of sample solution was intro- duced to the hydride generation reaction vessel, followed with $1 \mathrm{~mL}$ of $2 \mathrm{M} \mathrm{HCl}$ and $1.5 \mathrm{~mL}$ of $3 \% \mathrm{NaBH}_{4}$ reductant. The generated hydride gas was carried by argon to the gas liquid separator where any possible water residues were removed and the dry gas was transferred to the atomization section of the HGAFS or HGAAS.

For the proposed method, $10 \mathrm{~mL}$ of the aqueous sample solution or dissolved solid sample was transferred into the reaction vessel of the hydride generation system and vaporized to dryness using a rotary evaporator. Then $3 \mathrm{~mL}$ of $2 \mathrm{M}$ hydrochloric acid and $3 \mathrm{~mL}$ of $5 \%$ $\mathrm{NaBH}_{4}$ solution were added and the analysis was performed as described above for the conventional method.

\section{RESULTS AND DISCUSSION}

\section{Optimization}

The operating conditions for vaporization and analysis of the aqueous and dissolved samples were evaluated. The method of heating, time duration of vaporization to dryness, and volume of the aqueous sample solutions affect the vaporization process. Four devices for vaporization were evaluated: drying oven, hot plate, microwave, and rotary evaporatr using different volumes of standard solution at different temperatures.

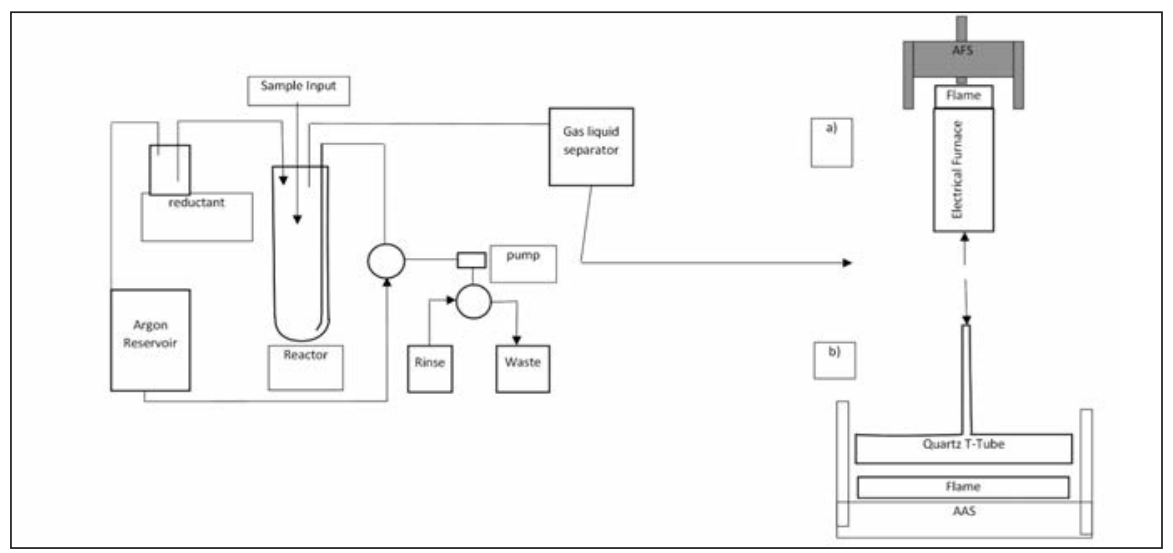

Fig. 1. Hydride generation setup with (a) AF and (b) FAA instrument.

\section{Atomic Apectroscopy 1 Vol. 38(6), Nov./Dec. 2017}

The parameters affecting hydride generation and carrying the hydride into the atomization section of the detection system are concentration and volume of the reductant and the acid, flow rate of the carrier gas, and size of the hydride generation reaction vessel. The carrier gas flow rate and the reaction vessel size are the most important parameters. A 20-ppb aqueous standard sample of $1,2,5,10$, and $20 \mathrm{~mL}$ was vaporized to complete dryness using the different heating devices and drying times. It was observed that the larger the sample volume, the longer the time duration for drying. The time duration was shortest with the rotary evaporator (Figure 2). On the other hand, a larger sample volume results in a higher signal and requires a longer time to dryness. The sample volume of $10 \mathrm{~mL}$ was found to be optimal with shortest time duration. For faster analysis with higher analyte concentrations, a smaller sample volume can be used or a larger sample volume for lower analyte concentrations.

In the next step, $10 \mathrm{~mL}$ of a 20 ppb standard sample was dried at different conditions (temperature or pressure) using the four drying devices. The recovery of the analyte was calculated by analyzing these standard solutions with the conventional method and also with the proposed method. The recoveries for all four drying methods were found to be nearly $100 \%$ at lowest temperature but at different time durations (see Figure 3). Highest recoveries together with lowest time durations of drying were always obtained by rotary evaporator and was therefore chosen as the optimized heating device for this study. A time duration of 15 minutes gave a recovery of $99.9 \%$. A faster analysis can be obtained with lower sample volume, for example, a 2-mL sample needs 7 minutes obtaining nearly the same recovery. 


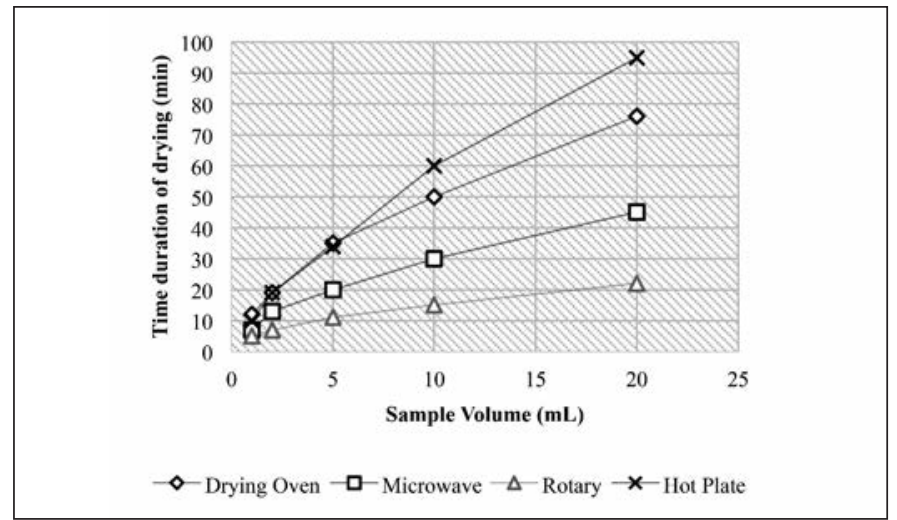

Fig. 2. Required time for complete drying of different volumes of a typical standard sample with various drying methods.

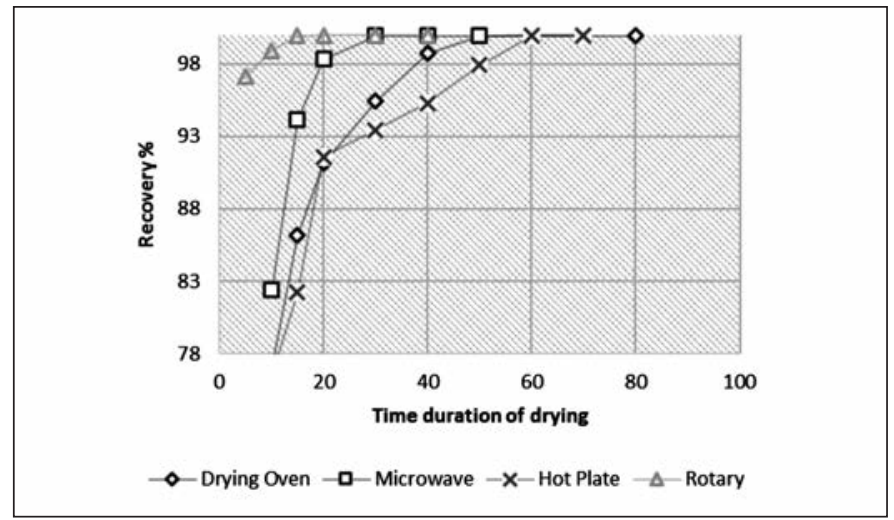

Fig. 3. Recoveries obtained by using various drying methods at different time durations.

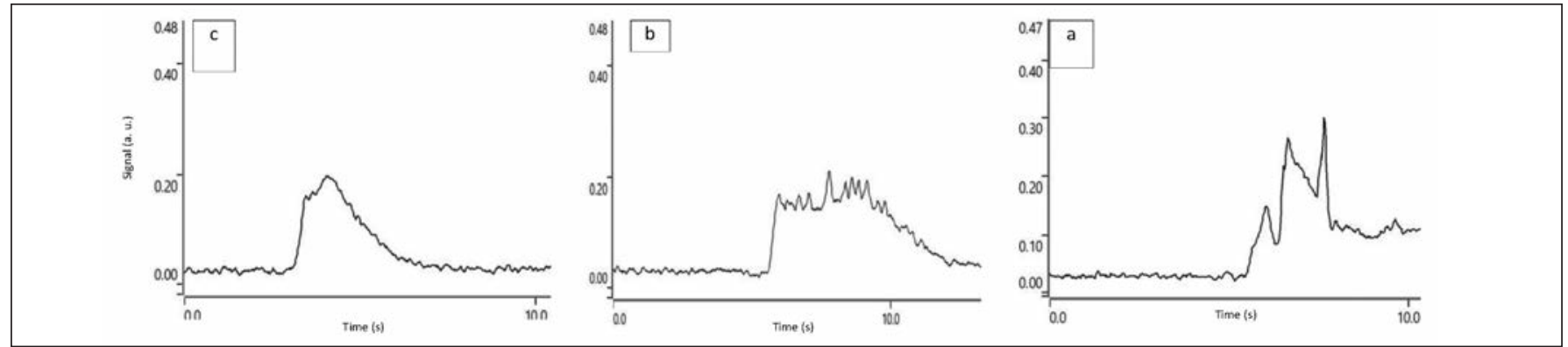

Fig. 4. Influence of carrier gas flow rate upon the shape of the output peak signal in the range of 20-75 $\mathrm{mL} / \mathrm{min}$ (a), 75-160 $\mathrm{mL} / \mathrm{min}(\mathrm{b})$, and 160-200 $\mathrm{mL} / \mathrm{min}$ (c).

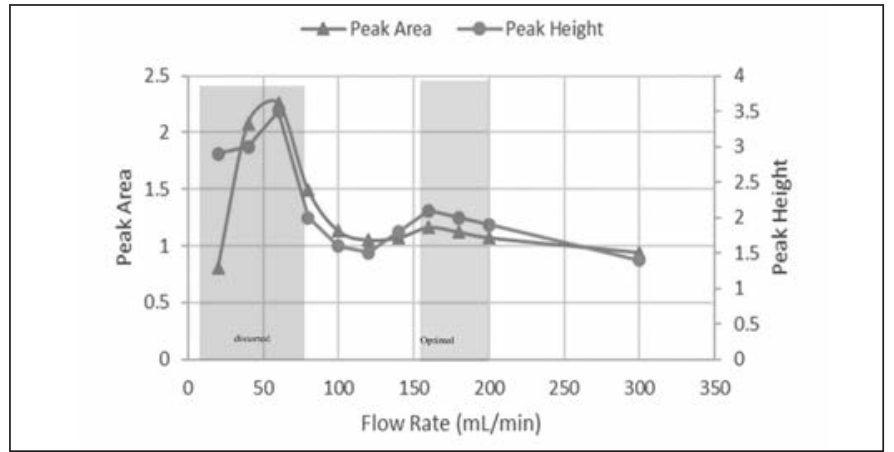

Fig. 5. Effect of flow rate of carrier gas on the area and beight of the output signal.

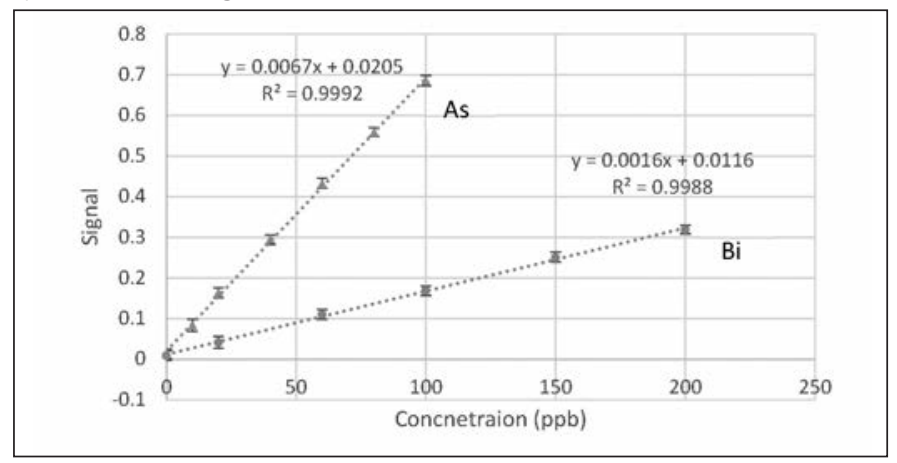

Figure 7: Calibration graph of arsenic and bismuth using the proposed HGAFS method.

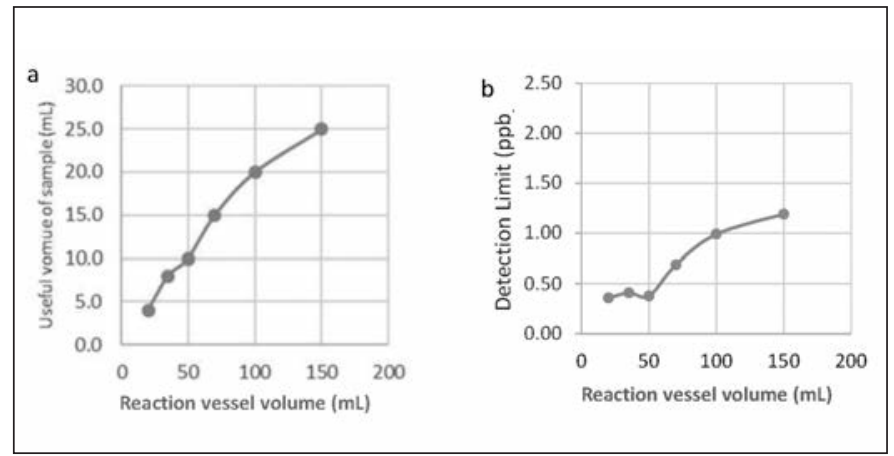

Fig. 6. Optimization of (a) useful volume of aqueous sample solution which can be analyzed and (b) the reactor size. 

affects both the magnitude and the shape of the signal peak. Higher flow rates lessen the generated hydride and tend to lower the signal. Lower flow rates can distort the signal peak due to the hydride gas pressure rather than the carrier gas and also because of inhomogeneous reaction of the reductant with the sample. Different flow rates of the carrier gas ranging from $20-200 \mathrm{~mL} / \mathrm{min}$ were applied for the analysis of a $10-\mathrm{mL}$ standard sample and the peak signals were recorded. Figure 4 shows peak distortion in the flow rate range of $20-75 \mathrm{~mL} / \mathrm{min}$, while in the $75-160$ $\mathrm{mL} / \mathrm{min}$ range peak distortion is diminished. Least distortion appears at the flow rates above $160 \mathrm{~mL} / \mathrm{min}$ and also changes the magnitude of the area and the height of the signal (see Figure 5). Thus, this flow rate was chosen as optimal for this study.

In the proposed method, since a definite volume of the sample solution was dried and then the residue analyzed, a preconcentration actually occurs. The higher volume of the sample results in more preconcentration, and using a larger size hydride generation reaction vessel permits using a higher sample volume. The maximum volume of an aqueous standard sample that can be vaporized in a specific size reaction vessel with the least distorted peak and an RSD equal to or less than $1.35 \%$ is considered the appropriate volume of the sample for that reaction vessel.
The flow rate of the carrier gas

A series of six round bottom flasks with variable volumes (20, $35,50,70,100,150 \mathrm{~mL}$ ) were used as the hydride generation reaction vessels. For the analysis of a standard sample, the appropriate volume for each of the reaction vessels was determined, see Figure 6a. The detection limits for each appropriate sample volume of each reaction vessel $\left(3 S_{b} / m\right.$, where $S_{b}$ and $m$ are the standard deviation and the slope of the calibration curve) was calculated. The results are shown in Figure 6b. As the volume in the reaction vessel increases, the analytical signal for the same amount of sample is reduced due to the dilution effect of the carrier gas. The appropriate sample volumes for all of these reaction vessels were found to be less than the volumes of these reaction vessels. However, with large sized reaction vessels, the difference is bigger (see Figure 6a). Figure 6b shows that best detection limit is obtained with the smallest size reaction vessels. The 50-mL reaction vessel with a $10-\mathrm{mL}$ sample volume was found to be the most acceptable reaction vessel for the proposed method. The recommended operating conditions for vaporization and analysis are listed in Table I.

Finally, to improve the detection limit further, several portions of 10-mL standard samples were added into the reaction vessel and vaporized one after the other. Using this multiple addition and vaporization process improved the detection limit significantly, but the recoveries were diminished.

TABLE I

Recommended Operating Conditions for Vaporization and Analysis

\begin{tabular}{ll} 
Operation & Recommended Conditions \\
\hline Vaporization & Sample volume $(10 \mathrm{~mL})$ \\
& Vaporizatoin duration $(15 \mathrm{~min})$ \\
& Heating device (rotary evaporator)
\end{tabular}

Analysis $\quad$ Flow rate of carrier gas $(160 \mathrm{~mL} / \mathrm{min})$ Reaction vessel volume $(50 \mathrm{~mL})$

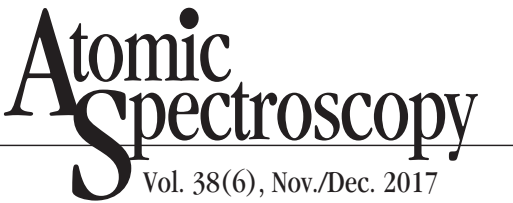

\section{Calibrations}

To construct the calibration curves for As and Bi, working standard solutions were prepared by diluting the stock solution of each analyte with a (1:1) mixture of $1 \mathrm{M}$ hydrochloric and sulfuric acid and $1 \mathrm{M}$ hydrochloric acid, respectively. Using the proposed HGAFS method under the optimized operating conditions, the working standard solutions were analyzed and the analytical curves for As and Bi constructed (see Figure 7).

The obtained sensitives for As and $\mathrm{Bi}$, defined as the slope of the calibration curve of the proposed method, were 0.33 and 0.13 , respectively. The calculated detection limits for As and Bi were 0.32 and $0.3 \mathrm{ppb}$, respectively. The precision of the proposed HGAFS method was evaluated by investigating the reproducibility of the measurement results and the drying conditions. The RSD $(n=5)$ values for As ad Bi were 1.46\% and 1.35\%, respectively. These figures of merit of the proposed HGAFS method were also compared with those obtained with the conventional hydride generation and HGAAS methods and the results are listed in Table II.

\section{Assessment of Proposed Method}

The accuracy and applicability of the proposed HGAFS method were evaluated by analyzing three certified reference soil samples: Soil TS-17, Soil TS-19, and NIST Soil (supplied by the Iranian Geological Research Center); three reference aqueous samples: Jajrood river water (Karaj, Iran), tap water and industrial wastewater (obtained from the Research Institute of Petroleum Industry of Iran); and four solid reference samples consisting of talc, lithium carbonate, bismuth sub-citrate (acquired from the Iranian pharmaceutical companies Actoverco, Arya, and Alhavi). The AAS instrument was also used 
as the detection technique to assess the capabilities of the proposed HGAFS method and its adaptability of the proposed sample preparation method to other atomic spectrometry system.

For arsenic determination, As(V) must be reduced to As(III) by using potassium iodide and stannous chloride prior to analysis (10). Solid sample preparation was initiated by dissolving $50 \mathrm{mg}$ of these solid samples with $10 \mathrm{~mL}$ of the appropriate acid solution in the hydride generation reaction vessel and then reducing As(IV) to As(III). For dissolving the lithium carbonate, bismuth subcitrate and talc samples, a (1:1) mixture of $1 \mathrm{M}$ hydrochloride and sulfuric acid was used and for road dust and the soil samples a $(5: 5: 5: 1)$
TABLE II

Comparison of Analytical Figures of Merit for Proposed HGAFS, HGAAS, and Conventional Methods

\begin{tabular}{llll}
\hline & $\begin{array}{c}\text { Calibration } \\
\text { Slope/Intercept }\end{array}$ & $\begin{array}{c}\text { RSD } \% \\
\text { (mid-range) }\end{array}$ & $\begin{array}{c}\text { LOD } \\
(\mathrm{ppb})\end{array}$ \\
\hline As & & & 1.0 \\
\hline Conventional & 0.02 & $1.30 \%$ & 0.32 \\
Presented HGAFS & 0.33 & $1.46 \%$ & 0.41 \\
Presented HGAAS & 0.05 & $1.70 \%$ & 1.0 \\
\hline Bi & & & 0.3 \\
\hline Conventional & 0.02 & $0.90 \%$ & 0.4 \\
Presented HGAFS & 0.13 & 1.35 & 1.46 \\
\hline Presented HGAAS & 0.08 & & \\
\hline
\end{tabular}

TABLE III

Assessment of Proposed Method by Analyzing Certified Reference Solid Samples and Reference Solid and Aqueous Sample Solutions Using HGAFS and HGAAS

\begin{tabular}{|c|c|c|c|c|c|}
\hline \multirow[t]{2}{*}{ Samples } & \multirow{2}{*}{$\begin{array}{l}\text { HGAFS } \\
\text { (ppb) }\end{array}$} & \multirow{2}{*}{$\begin{array}{c}\text { HGAAS } \\
\text { (ppb) }\end{array}$} & \multirow{2}{*}{$\begin{array}{l}\text { Cert. Value } \\
\text { (ppb) }\end{array}$} & \multicolumn{2}{|c|}{ Recovery(\%) } \\
\hline & & & & HGAFS & HGAAS \\
\hline \multicolumn{6}{|l|}{ As } \\
\hline Bismuth Subcitrate & $935.4 \pm 18$ & $928.2 \pm 25.0$ & $954.3 \pm 21.0^{\mathrm{a}}$ & $98.0 \%$ & $97.3 \%$ \\
\hline Jajrood River & $2.11 \pm 0.09$ & $2.17 \pm 0.15$ & $2.1 \pm 0.2^{\mathrm{a}}$ & $99.1 \%$ & $101.9 \%$ \\
\hline Industrial Wastewater & $6.12 \pm 0.22$ & $5.98 \pm 0.20$ & $6.5 \pm 0.4^{\mathrm{a}}$ & $94.0 \%$ & $91.9 \%$ \\
\hline Road dust & $6.85 \pm 0.2(\mathrm{ppm})$ & $6.74 \pm 0.17(\mathrm{ppm})$ & $7.0 \pm 0.3^{\mathrm{a}}(\mathrm{ppm})$ & $97.1 \%$ & $95.6 \%$ \\
\hline Soil TS-17 & $9.73 \pm 0.51(\mathrm{ppm})$ & $9.75 \pm 0.50(\mathrm{ppm})$ & $9.8 \pm 0.4^{\mathrm{d}}(\mathrm{ppm})$ & $99.0 \%$ & $99.2 \%$ \\
\hline Soil TS-19 & $13.12 \pm 0.60(\mathrm{ppm})$ & $13.12 \pm 0.65(\mathrm{ppm})$ & $13.2 \pm 0.6^{\mathrm{d}}(\mathrm{ppm})$ & $99.2 \%$ & $99.2 \%$ \\
\hline NIST soil & $2.12 \pm 0.13(\mathrm{ppm})$ & $2.13 \pm 0.10 \quad(\mathrm{ppm})$ & $2.1 \pm 0.2^{\mathrm{c}}(\mathrm{ppm})$ & $98.9 \%$ & $99.0 \% \%$ \\
\hline Talc & $2.87 \pm 0.13$ & $3.11 \pm 0.19$ & $3.02 \pm 0.2^{\mathrm{d}}$ & $95.0 \%$ & $103.0 \%$ \\
\hline Waste & $140.5 \pm 3.1$ & $139.5 \pm 2.5$ & $141.2 \pm 2.1^{\mathrm{a}}$ & $99.5 \%$ & $98.8 \%$ \\
\hline CCERCI Tap Water & $9.89 \pm 0.17$ & $10.16 \pm 0.15$ & $10 \pm 0.2^{\mathrm{a}, \mathrm{b}}$ & $98.9 \%$ & $101.0 \%$ \\
\hline Soil TS-17 & $1.91 \pm 0.12$ & $2.06 \pm 0.19$ & $2.2 \pm 0.2^{\mathrm{d}}$ & $86.4 \%$ & $90.5 \%$ \\
\hline Soil TS-19 & $2.21 \pm 0.16$ & $2.3 \pm 0.2$ & $2.6 \pm 0.3^{\mathrm{d}}$ & $84.7 \%$ & $88.1 \%$ \\
\hline Talc & $9.74 \pm 0.13$ & $10.21 \pm 0.22$ & $10 \pm 0.4^{\mathrm{a}, \mathrm{b}}$ & $97.4 \%$ & $102.1 \%$ \\
\hline
\end{tabular}

\footnotetext{
${ }^{a}$ Values obtained by applying a trusted analyzing method other than presented method.

${ }^{b}$ Values obtained by spiking the sample with $10 \mathrm{ppb}$ of standard.

${ }^{\mathrm{c}}$ Values obtained from a certified reference standard.

${ }^{\mathrm{d}}$ Value obtained from a certified secondary standard.
} 


\section{A $_{\text {Spectroscopy }}^{\text {tomic }}$ \\ Vol. 38(6), Nov./Dec. 2017}

mixture of $2 \mathrm{M} \mathrm{HCl}, \mathrm{HNO}_{3}, \mathrm{H}_{2} \mathrm{SO}_{4}$, and $\mathrm{HF}$ was used. Following the evaporation of these dissolved samples, the arsenic content was determined using the proposed HGAFS method.

The bismuth content of the solid samples was determined by the proposed HGAFS method after dissolving $50 \mathrm{mg}$ of finely powdered samples with $10 \mathrm{~mL}$ of $1 \mathrm{M}$ hydrochloric acid in the hydride generation reaction vessel, followed by vaporization to dryness of these solutions. The results of these assessments are listed in Table III.

\section{CONCLUSION}

The proposed direct HGAFS method requires less sample preparation and allows better detection limits in comparison with the conventional HGAFS methods. The agreement between the values obtained for the certified reference solid samples, the reference solid and aqueous sample solutions, and those of the certified values were satisfactory and found to be between $97.1 \%$ and $99.2 \%$ for As and $84.7 \%$ and $99.6 \%$ for Bi. Good agreement for As and Bi was found between the obtained results for the proposed HGAFS and the conventional HGAAS with $\mathrm{RSD}(\mathrm{n}=5)$ values of $1.46 \%$ and $1.35 \%$, sensitivities (as the calibration curve) of 0.33 and 0.13 , and the detection limits of 0.32 and $0.3 \mathrm{ppb}$, respectively. The proposed HGAFS system can be used as a direct solid sampling and preconcentration method for the analysis of solid samples and aqueous sample solutions.

\section{ACKNOWLEDGMENT}

The authors give thanks to the Geological Research Center of Iran, in particular to Dr. N. Zari and Ms. M. Ahmadi for sharing their pearls of wisdom with us during the course of this research.

\section{REFERENCES}

1. P. Török, M. Žemberyová a, Spectrochim. Acta B 71, 80 (2012).

2. Iwashita, T. Nakajima, $H$. Takanashi, A. Ohki, Y. Fujita, and T. Yamashita, Talanta 1(1), 251 (2007).

3. J. R. Otero-Rey, M. J. Mato-Fernandez, J. Moreda-Pineiro, E. AlonsoRodriguez, S. Muniategui Lorenzo, P. Lopez-Mahıa, and D. PradaRodriguez, Anal. Chim. Acta 531(2), 299 (2005).

4. K. Srogi, Anal. Lett. 40, 2, 199 (2007).

5. E. d. Oliveira, Braz. Chem. Soc. 14 , 2, 174 (2003).

6. J. Dedina, D. L. Tsalev, and J. Winefordner, Hydride generation atomic absorption spec-trometry. Wiley Chichester (1995).

7. J. Dedina, Spectrochim. Acta B 62 , 9, 846 (2007).

8. L. Garc' 1 a, M. J. V. Mart 'inez, and M. H. Cordoba, J. Anal. At. Spectrom. 6, 8, 627 (1991).

9. Norman, Nicholas C (1998). Chemistry of Arsenic, Antimony and Bismuth. Springer. p. 50. ISBN 978-0-7514-0389-3.

10. Maja Welna, Trends Anal. Chem.; TrAC 65, 122 (2015). 